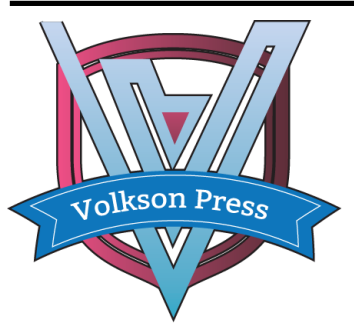

Contents List available at VOLKSON PRESS

New Materials and Intelligent Manufacturing (NMIM)

DOI : http://doi.org/10.26480/icnmim.01.2018.40.42

Journal Homepage: https://topicsonchemeng.org.my/

ISBN: 978-1-948012-12-6

\title{
DESIGN OF AUTOMATION INSTRUMENT EXPERIMENT SYSTEM MONITORING SYSTEM BASED ON WINCC
}

\author{
Hu Xiaoyan ${ }^{1 *}$, Meng Yanan1 ${ }^{1}$, Zhai Yupeng ${ }^{2}$ \\ ${ }^{1}$ School of information and control engineering, Jilin Institute of Chemical Technology Chengde Street, Jilin, China. \\ ${ }^{2}$ Instrument workshop, PetroChina Jilin Petrochemical Co chemical fertilizer plant, Jilin, China. \\ *Corresponding Author Email: 779078328@qq.com
}

This is an open access article distributed under the Creative Commons Attribution License, which permits unrestricted use, distribution, and reproduction in any medium, provided the original work is properly cited

\section{ARTICLE DETAILS ABSTRACT}

Article History:

Received 26 June 2018

Accepted 2 July 2018

Available online 1 August 2018

On the basis of expounding and analyzing the experimental requirements of the flow level instrument system, temperature instrument system and pressure instrument system, the automatic instrument experimental monitoring system establishes the control scheme of the instrument experiment system. The WinCC configuration software is used to design the picture drawing, dynamic connection, history library establishment, picture drawing, history curve and alarm, etc., so as to realize the data detection and record of the liquid level and flow. At the same time, when the data has problems, it can alarm in time, complete the dynamic scanning and analysis of the data, and provide a certain theoretical basis for the stable operation of the experiment in operation.

\section{KEYWORDS}

Control Scheme, Monitoring System, Instrument System.

\section{INTRODUCTION}

With the rapid development of science and technology and the continuous improvement of automation, China's instrument industry will also undergo new changes and gain new developments. For a long period of domestic understanding and investigation, the types of automated instruments provided on the experimental platform are few and could not meet the requirements. As a typical high-tech product, modern instrumentation is rapidly developing toward computerization and multifunctionalization, and is moving toward higher-speed, more reliable access to the full range of information that is analyzed, detected, and controlled [1].

\section{INSTRUMENTATION SYSTEM}

The automatic instrument experimental device mainly consists of several parameters measuring the chemical process, including flow rate, liquid level, temperature and pressure. All kinds of instruments and common parameters in chemical process control industry can be detected and measured.

The system consists of two sinks and some pipes. The normal temperature water in the V102 sink is removed from the pump P101, and enters the V101 through the various flowmeters. The water from the sink V101 flows to the V102 through the bottom outlet and forms a closed loop. When working, only one way is chosen for one way, and the other branch valves are closed. The installed flowmeter has orifice plate flowmeter, electromagnetic flowmeter, glass rotor flowmeter and turbine flowmeter. In the sink V101, install the liquid level meter to check its liquid level, including the glass plate level gauge, the static pressure level gauge and the ultrasonic level gauge.

\section{DESIGN OF INSTRUMENT MONITORING SYSTEM}

On the basis of the research on the process flow of the instrument experiment system, the design of database, picture drawing, dynamic connection, history library definition, historical trend curve design and historical alarm are designed by WINCC software [2,3].

\subsection{Building a project}

Start the WINCC project manager, select the project type as a single user project, enter the name of the project, click OK and finish the creation of the new project.

\subsection{The establishment of process variables}

Configuration variables in WINCC are divided into two categories: internal variables and process variables. Internal variables are mainly used for the definition of internal dynamic calculations [4]. Process variables are used to connect external process data. The four variables of DI, DO, AI and AO are established based on I/O point table. Take the establishment of the DI point as an example. First click the DI variable group with the right mouse button, and then click "New Variable" to call out the variable attribute screen. Then enter P101RUN in the name position, select the binary data type, and click the address bar. Select the button to open the address properties screen, the data type to select the input, the address should select I0, the bit is 0 , as shown in Figure 1.

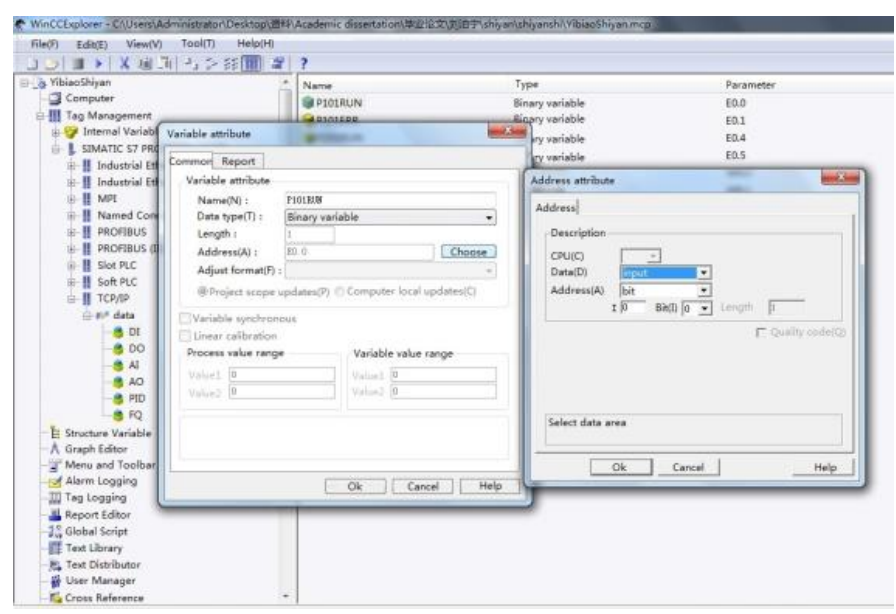

Figure 1: The establishment of variables 


\subsection{Create and draw pictures}

During configuration, the graphic system is used to create a picture of the display process in the running system. The graphic editor is the configuration software of graphics system and is an editor for creating process pictures [5].

Create a picture according to the process flow chart, then click the graphic editor, then click the right key in the blank, select the "new picture" and click the right key on the appearance, enter "YW\&LL", and then double click the screen "YW\&LL". Open the graphics editor to edit the screen.

\subsubsection{Definition of picture attributes}

Open the graphics editing screen, select the "attribute" > "object property" $>$ "geometry" dialog box, in which the parameters can be set to modify the corresponding parameters in "static", the width and height of the screen are modified to 1366 and 768 respectively (the same as the current resolution of the computer).

\subsubsection{Equipment drawing}

Click the menu "View > Library" to display the object directory in the object library. Double-click "Global Library" to display the directory tree in the global library, then select the valve and drag it to the screen.

\subsection{Dynamic connection}

Through dynamic linking, we can dynamically transform object properties to achieve intuitive visual effects. In this way, the picture is more intuitive and the operation is more convenient. There are 4 kinds of dynamic connections in the design, they are numerical display, liquid filling, color change and display concealment.

\subsubsection{The change in the color of the pump}

In the system, the start-stop state and the fault state of pump need to be displayed intuitively, so we need to set the color change of pump [6]. When the pump is in start-up state, the color of the pump body is green. When the pump is in trouble, the pump body is red. Then right-click the pump, in the "Properties" dialog box, select the "Control Properties" of the pump, and set the dynamic dialog box for the "Fore Color", as shown in Figure 2.

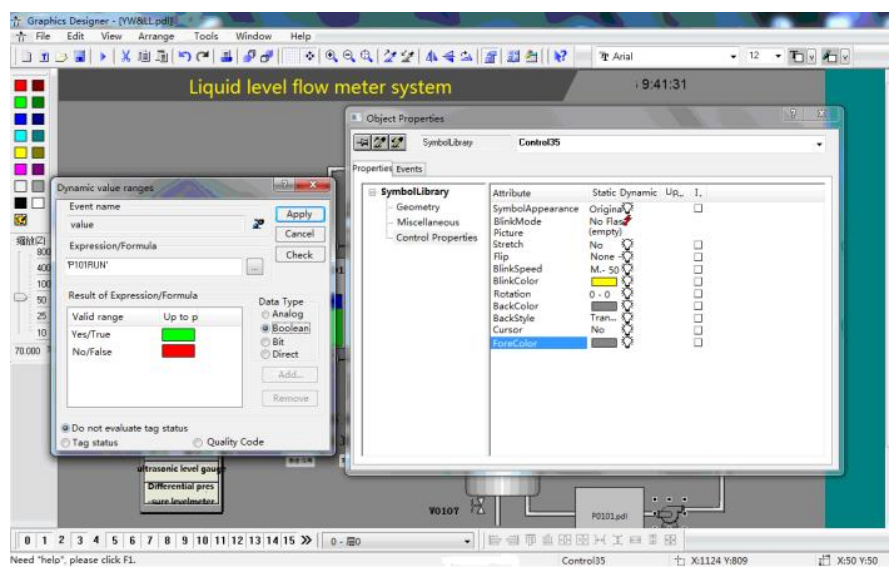

Figure 2: Setting the color change of the pump

Connect the "P101RUN" variable, when the variable value is 1 , the color of the pump body will be green. When the variable value is 0 , the pump body will be red.

\subsubsection{The flicker setting of the pump}

When the pump fails, the pump shows a flickering state. Right click the pump body, select the "control property" of the pump in the properties dialog box, and set the dynamic dialog box for "Blink Mode" in the dialog, as shown in Figure 3.

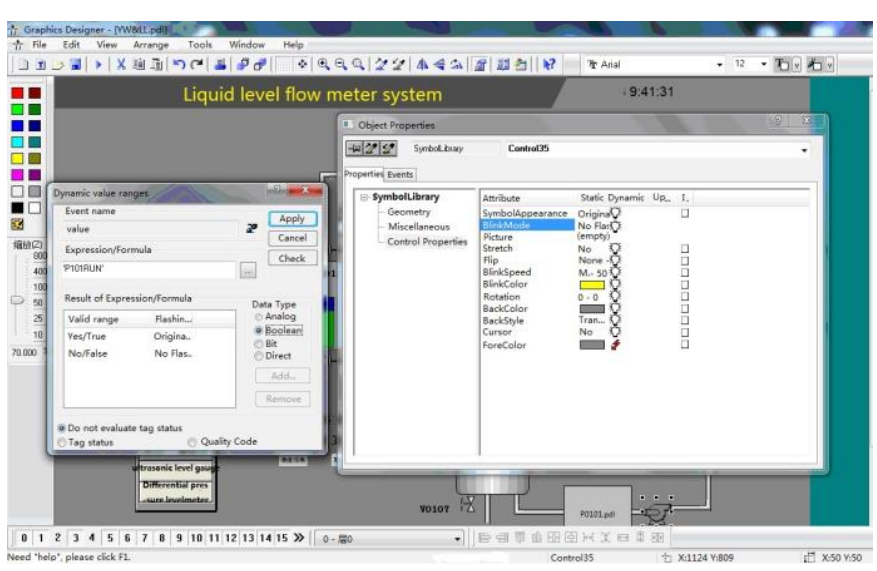

Figure 3: Set the flicker of the pump

Connect the "P101ERR" variable. When the variable value is 1 , the pump body will show the effect of flickering. When the variable value is 0 , the pump body will not change.

\subsection{Design of alarm}

The alarm record is divided into two components: configuration system and operation system. Alarm records provide display and operation options to get and archive results [7]. In the picture, the process alarm point is connected to the alarm. Once an alarm occurs, it will record in this picture. Through this picture, it is convenient to look up the abnormal phenomenon and analyze the fault. From the picture, we can see the name of the specific point, the alarm time, the type of alarm and so on.

First, activate the analog alarm, and right-click the new alarm, set the LI0101 property in the property dialog box. The upper limit of setting the limit is 90 , the lower limit is 10 , and the message number is 2 . The table window can automatically increase the information of the two alarm configurations numbered 1 and 2 .

\subsection{Design of online trend map}

In the design of instrument experiment system, a total of four online trend graphs were created: temperature trend curve, pressure trend curve, flow trend curve, and liquid level trend curve. The traffic trend curve will be highlighted here. The other methods are similar.

In the graphics editor, select the control object on the object palette [8]. Select "WINCC Online Trend Control", place the mouse pointing to the position of the trend curve in the screen area, drag to the desired size after the release, there will be the "WINCC online trend control properties" dialog box.

Click the "regular" interface, the window title is LI0101, select the archive data in the "open screen"; select the archive variable in the data source option; select the status bar, the toolbar and the resizing option in the display bar; and the rewriter direction is selected to the right; finally, select the public $\mathrm{X}$ axis and the public $\mathrm{Y}$ axis on the interface. Click the confirm button, as shown in Figure 4.

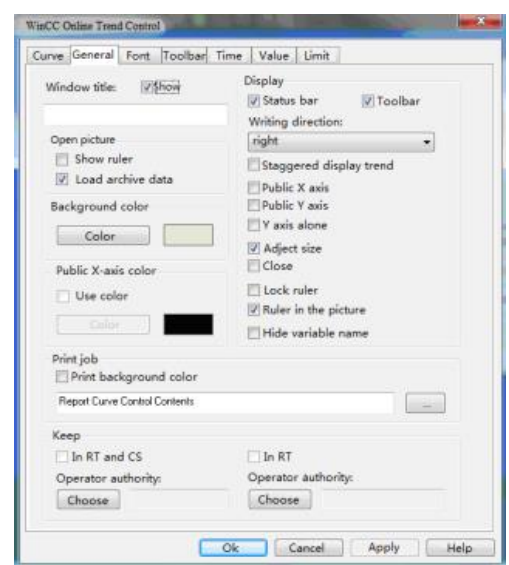

Figure 4: The conventional interface of flow trend curve 


\subsection{The design of the help file in the experiment}

In order to make it easier for students to use the experimental system, and let them understand the experimental requirements and experimental purposes as well as the experimental procedures, a help file has been designed here. The specific steps are as follows:

A new picture is named "experiment one guide". At the same time, we open this picture and input the content of help file in the picture.

Then open the "YW\&LL" screen again, add a picture window to the picture, and name it "experiment one guide". A picture exhalation button is added to the top right corner of the flowchart named "experiment guide" and a "close" button. The dynamic connection of the small screen and the button is used to dynamically connect the small screen of the help file and the button. As shown in Figure 5.

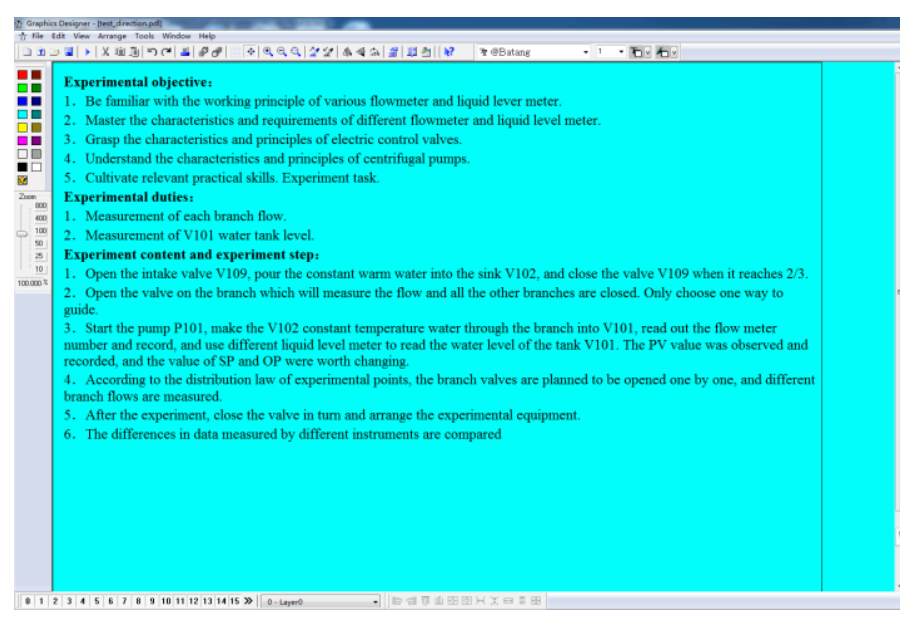

Figure 5: Screen display of help file

\section{CONCLUSION}

Based on the research on the process characteristics, main process parameters and control requirements of the instrument experimental system, the control scheme of the instrument experimental system was determined on this basis. The monitoring of the instrument experiment system is developed and designed by using WINCC monitoring software, and the monitoring functions of data monitoring, historical trend record and alarm record are realized in the process.

\section{ABOUT THE AUTHORS}

Hu Xiaoyan(1993-): Female, Postgraduate, Graduated from Jilin Institute of Chemical Technology. Now studying in the control engineering major of Jilin Institute of Chemical Technology. The main research direction is the integration of advanced control algorithm research and control system.

Meng Yanan(1969-):Female, Professor of Jilin Institute of Chemical Technology, The leader in the discipline of control theory and control engineering, mainly engaged in distributed control system and PLC system development and engineering application as well as advanced control theory research.

Zhai Yupeng(1980-):Engineer,Graduated from the automation major of Jilin Institute of Chemical Technology. Now he has been working in the PetroChina Jilin Petrochemical Co, mainly engaged in the maintenance and research of the DCS/SIS control system.

\section{REFERENCES}

[1] Wang, S.X. 2007. Industrial process control engineering. Beijing,China:Chemical Industry Press.

[2] Lu, J.H. 2000. Use WINCC to realize process monitoring. Journal of Wuhan University of Science and Technology (Natural Science Edition), 5 (3), 35-56.

[3] Wang, Z.K. 2005. The application of PLC and WINCC configuration software in automatic control. China Science and technology information, 5 (7), 77-89.

[4] Sun, F. 2013. System dynamic optimization method and application based on intelligent calculation. Doctoral dissertation, East China university of science and technology, Shanghai, China.

[5] Cao, L., Zhang, B.F., Zhang, Y. 2000. Automatic monitoring technology and instrument control system . Beijing,China: Chemical Industry Press.

[6] Qi, Y.J.,Wang, Y.A.,Yin, H.S. 2010. Monitoring system of oilfield injection pump based on Labview. Science and technology and engineering, 10 (9), 2176-2179.

[7] Li, J.T. 2015. Analysis of dynamic workshop monitoring system based on configuration technology. Chemical management, 2, 135-136.

[8] Chen, S.L., Zhao, Q.Q., Zhang, H.G. 2003. An object-oriented power system graphical editor and its application in SCADA. Power supply, 20 (3), 32-33 